\title{
A compounding analysis of plural reduplication
}

\author{
Yuta Tatsumi*
}

\begin{abstract}
The paper offers an analysis of plural reduplication in Japanese. I argue that reduplicated nouns are antonym compounds that have two opposite values of number features. Each member of a reduplicated noun is associated with an interpretable valued number feature, and values of the number features must not be identical to each other. I propose that two opposite values on the top node of a reduplicated noun becomes an uninterpretable valued feature in Japanese. As a result, reduplicated nouns in Japanese are not specified as singular or plural because uninterpretable features do not have any semantic import. The proposal makes the prediction that reduplicated nouns are similar to bare common nouns in the sense that they do not bear the specification of singular-plural distinction. I show this prediction is borne out. The proposal also leaves room for an analysis of typological variation of plural reduplication.
\end{abstract}

Keywords. plural reduplication; compounding; number features; Japanese

1. Introduction. This paper provides an analysis of plural interpretation in Japanese. As shown in (1a), Japanese bare common nouns are ambiguous between singular and plural. However, when a noun undergoes plural reduplication, the resulting noun is interpreted only as plural, as can be seen in (1b).
a. Taro-ga [hasit-teiru hito]-o mita.
Taro-NOM run-ASP person-ACC saw
'Taro saw \{person | people $\}$ who \{is $\mid$ are $\}$ running.'
b. Taro-ga [hasit-teiru hito-bito]-o mita.
Taro-NOM run-ASP person-person-ACC saw
'Taro saw people who are running.'

The unavailability of a singular interpretation in (1b) can be demonstrated by using modification by the numeral 'one'. Due to the semantic nature, the numeral 'one' requires singular individuals. As shown in (2a), Japanese bare common nouns can be modified by the numeral 'one' because they are ambiguous between singular and plural. In contrast, reduplicated nouns are incompatible with the numeral 'one', as shown in (2b).
a. Taro-ga [hasit-teiru hito-ri-no
Taro-NOM run-ASP one-CLS-GEN
'Taro saw one person who is running.'
b. * Taro-ga [hasit-teiru hito-ri-no hito-bito]-o mita.

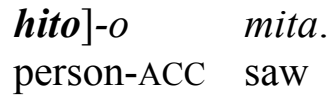

The unacceptability of ( $2 b)$ shows that reduplicated nouns cannot receive a singular interpretation. In this study, I argue that although reduplicated nouns cannot be interpreted as singular, they denote a set of individuals, including both plural and singular individuals. In this respect,

\footnotetext{
* I would like to thank the audience at the LSA 2018 Annual Meeting.

Author: Yuta Tatsumi, University of Connecticut (yuta.tatsumi@uconn.edu).
} 
reduplicated nouns are similar to bare common nouns. These two types of noun in Japanese denote an entire semi-lattice (Chierchia 1998, 2010), and what is special about plural reduplication is the lack of singular interpretations.

2. Japanese plural reduplication. In this section, I introduce basic properties of Japanese plural reduplication. First, Japanese plural reduplication is not fully productive. A comprehensive list of nouns that can undergo plural reduplication is given in (3). To my knowledge, there are only around fifteen nouns that can undergo plural reduplication in modern Japanese.

Japanese plural reduplication
eda-eda 'branch-branch' = branches
hito-bito 'person-person' = people
husi-busi 'joint-joint' = joints
ie-ie 'house-house' = houses
ki-gi 'tree-tree' = trees
mura-mura 'village-village' = villages
sina-zina 'item-item' = items

hana-bana 'flower-flower' = flowers

$h i$-bi 'day-day' = days

hosi-bosi 'star-star' = stars

kami-gami 'god-god' = gods

kuni-guni 'country-country' = countries

sima-zima 'island-island' = islands

yama-yama 'mountain-mountain' = mountains

Second, Japanese plural reduplication exhibits sequential voicing (also known as Rendaku) when applicable. As shown in (4a), the first consonant of the second member of a reduplicated noun is voiced. If the first consonant of the second member is not voiced, the resulting forms are unacceptable, as can be seen in (4b).
a. hana-bana 'flower-flower' = flowers
$\underline{h i-b i}$ 'day-day' = days, etc.

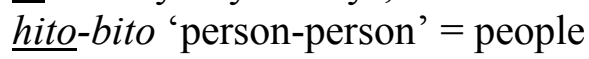
$\underline{k i-g i}$ 'tree-tree' $=$ trees

b. *hana-hana 'flower-flower' = flowers
* $h i$ - $h i$ 'day-day' = days
*hito-hito 'person-person' = people
$* k i-k i$ 'tree-tree' $=$ tree

Third, only mono- or bisyllabic nouns can undergo plural reduplication, as shown in (5).
a. hana-bana 'flower-flower' = flowers
$\underline{h i-b i}$ 'day-day' = days
hito-bito 'person-person' = people
b. *gakusei-gakusei 'student-student' = students
*ringo-ringo 'apple-apple' = apples
*otoko-otoko 'man-man' = men

This morphophonological property may be related to the fact that nouns which can undergo plural reduplication is limited in Japanese. However, it is not the case that all mono- or bisyllabic nouns can undergo plural reduplication. For example, ${ }^{*} i n u-i n u$ 'dog-dog' $=$ dogs is unacceptable.

3. Analysis. I would first like to introduce my analysis of Japanese plural reduplication, and then I provide support for the proposal in Section 4.

3.1. SYNTAX: PLURAL REDUPLICATION AS ANTONYM COMPOUNDING. I propose that reduplicated nouns are antonym compounds that have two opposite values of number features. In antonym compounds, semantically contrasted elements are combined. Examples of Japanese antonym compounds are given in (6).

Japanese antonym compounds
a. tyuu-ya 'day-night' = whole day
b. dai-syoo 'big-small' = size
c. bai-bai 'sell-buy' = trade
d. ati-koti 'there-here' = everywhere

I propose that Japanese plural reduplication is an example of antonym compounding. (See Inkelas \& Zoll 2005 for a compounding analysis of reduplication.) Specifically, I assume (i) that 
each member of a reduplicated noun is associated with an interpretable number feature, and (ii) that values of interpretable number features must not be identical to each other, as shown in (7). Under the present analysis, reduplicated nouns are antonym compounds in the sense that values of two interpretable number features are opposite and contrasted.
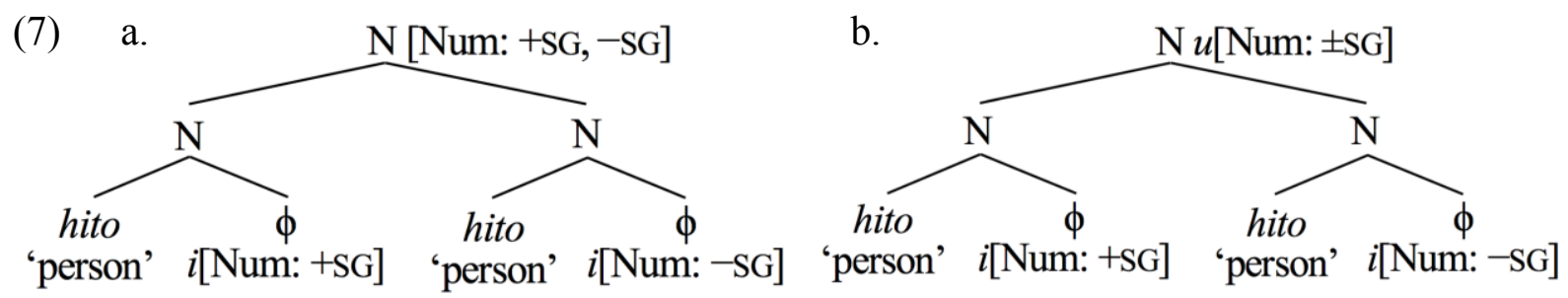

Each number feature attached to an $\mathrm{N}$ is percolated to the top node. As a result, the top node bears two opposite values, as in (7a). Based on Harbour (2011), I assume that the two opposite values on the top node of a reduplicated noun yield an uninterpretable valued feature, as represented in (7b). The number feature on the top node in (7b) is uninterpretable, but it bears the two opposite values. Therefore, it is an uninterpretable unvalued feature (i.e. $u[\mathrm{~F}: \mathrm{val}]$ ), according to Pesetsky \& Torrego's (2007) classification of features. I assume here that unvalued features must be valued before the output of the syntax is sent to the interfaces. Under this assumption, the presence of an uninterpretable valued feature does not cause any problem in the syntax.

3.2. SEMANTICS. Japanese bare common nouns are ambiguous between singular and plural. Following Chierchia's $(1998,2010)$ approach to bare nominals, I assume that Japanese bare common nouns are kind-denoting terms as in (8a), and their denotations correspond to join semilattices. For example, hito 'person/people' refers to the totality of people in a given world. Japanese bare common nouns are turned into type $<\mathrm{e}, \mathrm{t}>$ by the ${ }^{\cup}$ function, as in (8c).
a. $\llbracket$ hito $\rrbracket^{w, g, c}=$ PERSON $_{\mathrm{W}}$
c. $\llbracket\left[{ }^{\cup}\right.$ hito $] \rrbracket^{w, g, c}=\lambda \mathrm{x} \cdot\left[\mathrm{x} \leq\right.$ PERSON $\left._{\mathrm{w}}\right]$
b. $\llbracket \cup \rrbracket^{w, g, c}=\lambda \mathrm{Y}_{\mathrm{w}} \cdot \lambda \mathrm{x} \cdot\left[\mathrm{x} \leq \mathrm{Y}_{\mathrm{w}}\right]$

I assume that in order to obtain singular interpretations, Japanese bare common nouns must combine with $i[\mathrm{Num}:+\mathrm{SG}]$. The denotations of interpretable number features are given in (9).
a. $\llbracket i[\mathrm{Num:}+\mathrm{SG}] \rrbracket^{w, g, c}=\lambda \mathrm{P}_{<\mathrm{e}, \downarrow} \cdot \lambda \mathrm{x}_{\mathrm{e}} \cdot[\mathrm{P}(\mathrm{x}) \wedge \neg \exists \mathrm{y}[\mathrm{y} \leq \mathrm{x} \wedge \mathrm{P}(\mathrm{y})]]$
b. $\llbracket i[\mathrm{Num}:-\mathrm{SG}] \rrbracket^{w, g, c}=\lambda \mathrm{P}_{<\mathrm{e}, \downarrow} \cdot \lambda \mathrm{x}_{\mathrm{e}} \cdot[\mathrm{P}(\mathrm{x}) \wedge \exists \mathrm{y}[\mathrm{y} \leq \mathrm{x} \wedge \mathrm{P}(\mathrm{y})]]$

The semantic computation of a singular interpretation of a common noun is represented in (10).

$$
\begin{aligned}
\mathbb{I} & {\left[\left[{ }^{\cup} \text { hito }\right] i[\mathrm{Num}:+\mathrm{SG}]\right] \rrbracket^{w, g, c} } \\
& =\lambda \mathrm{P}<\mathrm{e}, \triangleright \cdot\rangle \cdot \lambda \mathrm{z}_{\mathrm{e}} \cdot[\mathrm{P}(\mathrm{z}) \wedge \neg \exists \mathrm{y}[\mathrm{y} \leq \mathrm{z} \wedge \mathrm{P}(\mathrm{y})]]\left(\lambda \mathrm{x} \cdot\left[\mathrm{x} \leq \text { PERSON }_{\mathrm{w}}\right]\right) \\
& =\lambda \mathrm{z}_{\mathrm{e}} \cdot\left[\mathrm{z} \leq \mathrm{PERSON}_{\mathrm{w}} \wedge \neg \exists \mathrm{y}\left[\mathrm{y} \leq \mathrm{z} \wedge \mathrm{y} \leq \text { PERSON }_{\mathrm{w}}\right]\right]
\end{aligned}
$$

In (10), the resulting noun denotes a set of singular entities. As for plural interpretations, I assume that common nouns are tied with $i[\mathrm{Num}:-\mathrm{SG}]$. The semantic computation of a plural interpretation of a common noun is represented in (11).

$$
\begin{aligned}
& \mathbb{\llbracket}\left[\left[{ }^{\cup} \text { hito }\right] i[\text { Num: }-\mathrm{SG}]\right] \mathbb{1}^{w, g, c} \\
& \quad=\lambda \mathrm{P}<\mathrm{e}, \triangleright \cdot \lambda \mathrm{ze}_{\mathrm{e}} \cdot[\mathrm{P}(\mathrm{z}) \wedge \exists \mathrm{y}[\mathrm{y} \leq \mathrm{z} \wedge \mathrm{P}(\mathrm{y})]]\left(\lambda \mathrm{x} .\left[\mathrm{x} \leq \text { PERSON }_{\mathrm{w}}\right]\right) \\
& \quad=\lambda \mathrm{z}_{\mathrm{e}} \cdot\left[\mathrm{z} \leq \operatorname{PERSON}_{\mathrm{w}} \wedge \exists \mathrm{y}\left[\mathrm{y} \leq \mathrm{z} \wedge \mathrm{y} \leq \text { PERSON }_{\mathrm{w}}\right]\right]
\end{aligned}
$$


In (11), the resulting noun denotes a set of plural entities, excluding singular ones. (12) illustrates possible denotations of Japanese common nouns under the present analysis. Although Chierchia $(1998,2010)$ assume that the top element in the semilattice in (12) corresponds to the denotation of a kind-denoting term, I assume here that the extension of a kind-denoting term corresponds to the entire semilattice in (12), for expository purposes. The top element in (12) denotes the totality of the elements below it, and the crux of Chierchia's analysis lies in the assumption that the extension of a kind corresponds to the totality of all instances of it in a given world.

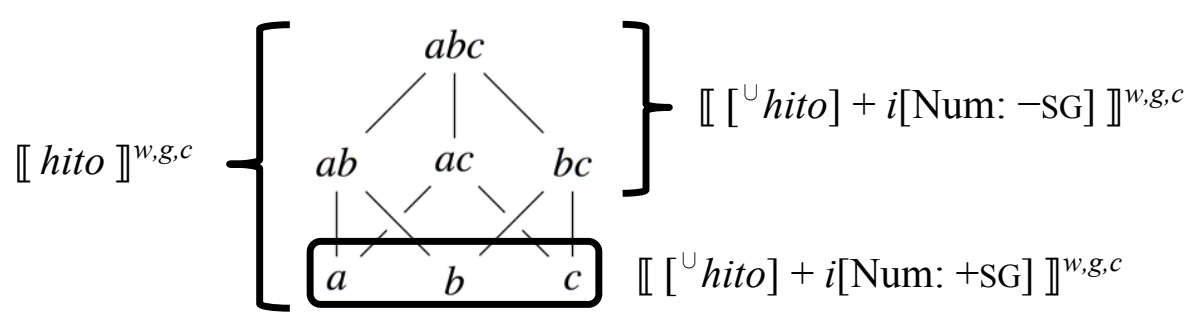

Under the present analysis, in order to obtain singular interpretations, $i$ [Num: $+\mathrm{SG}]$ must be present in a structure. However, two opposite values on the top node of a reduplicated noun yield an uninterpretable feature. This means that there is no way for $i[\mathrm{Num}:+\mathrm{SG}]$ to survive in plural reduplication. This is the reason why singular interpretations are unavailable in plural reduplication.

4. Support. The number feature on the top node of a reduplicated noun is uninterpretable. Uninterpretable features do not have any semantic import, and the present analysis will predict that reduplicated nouns are similar to bare common nouns in the sense that they do not exhibit the singular-plural distinction. In this section, I examine similarities between bare common nouns and reduplicated nouns.

4.1. THE PLURAL MORPHEME TATI. In addition to plural reduplication, Japanese has another way to express nominal plurality. If a noun is marked by the associative marker tati, the resulting noun receives a plural interpretation. As shown in (13), tati can combine with a proper noun or a common noun. Nouns with tati receive an associative reading or an additive reading. When tati attaches to a proper name, the associative reading is preferred over the additive one, but the additive reading is still possible in (13a). Common nouns with tati do not have this preference, and both readings are possible in $(13 b)$.
a. [ Taro ]-tati-ga
kita.
Taro-PL-NOM
came
'People named "Taro" came.'
'A group represented by Taro came.'
b. [gakusei ]-tati-ga kita.
student-PL-NOM came
'Students came.'

'A group represented by students came.'

[additive reading]

[associative reading]

[additive reading]

[associative reading]

If plural reduplication expresses nominal plurality like the plural morpheme tati, it will be expected that when tati combines with a reduplicated noun, the resulting noun phrase sounds unnatural because both tati and plural reduplication mark nominal plurality, and they are redundant. However, this expectation is not borne out. As shown in (14b), plural reduplication is compatible with the plural morpheme tati. Importantly, bare common nouns behave like reduplicated nouns in this respect, as shown in (14a). 

a. Taro-ga [Yamada-ke-no hito-tati]-o atsumeta.
Taro-NOM Yamada-family-GEN person-PL-ACC gathered
'Taro got the Yamadas together.'
b. Taro-ga [Yamada-ke-no hito-bito-tati]-o atsumeta.
Taro-NOM Yamada-family-GEN person-person-PL-ACC gathered
'Taro got the Yamadas together.'
[bare nouns]

The acceptability of (14b) can be captured under the present analysis. Nouns which undergo plural reduplication do not have the singular-plural distinction, just like bare common nouns.

Whatever the nature of the plural morpheme tati, it is not surprising that reduplicated nouns can co-occur with the plural morpheme tati under my analysis. (For a semantic and syntactic analysis of the plural morpheme tati, see Kurafuji (2004) Nakanishi \& Tomioka (2004), Tatsumi (2017) and references therein.) It may be worth noting here that plural reduplication in Thai is also compatible with another plural marker. Thai has the associative/group plural marker phuak, which derives plural interpretations. As shown in (15), phûak can co-occur with plural reduplication in Thai, like Japanese. Given the similarity between Japanese and Thai, it is not unreasonable to say that the resent analysis could be extended to plural reduplication in Thai.

(15) Thai (Jenks 2011: 101-102)
a. phûak-dèk jay maj group-child still not do homework

'The children still haven't done their homework.'
b. phûak-dèk-dèk
jay mâj
tham kaan-bâan.
group-child-child
still not
do homework

'The children still haven't done their homework.'

4.2. PluRAlity INFERENCES. Sudo (2015) observes that Japanese reduplicated nouns can have number neutral denotations in some environments. In (16a), a reduplicated noun appears with sentential negation. In this case, the sentence is true in a situation where Taro did not pick up any flower including a single one. Without sentential negation, reduplicated nouns express the nominal plurality, as shown in (16b). (16b) is true only if Taro picked more than one flower.
a. Taro-wa
[ niwa-no
hana-bana]-o
tsum-anakat-ta.
Taro-TOP garden-GEN
flower-flower-ACC
pick-NEG-PST
'Taro did not pick flowers in the garden.'
b. Taro-wa [niwa-no hana-bana]-o tsunda.
Taro-TOP garden-GEN flower-flower-ACC picked
'Taro picked more than one flower in the garden.'

In this respect, Japanese bare common nouns behave like reduplicated nouns, as shown in (17). The sentence is true in a situation where Taro did not pick up any flower including a single one.

$\begin{array}{lccc}\text { Taro-wa } & \text { niwa-no } & \text { hana }]-o & \text { tsum-anakat-ta. } \\ \text { Taro-TOP } & \text { garden-GEN } & \text { flower-ACC } & \text { pick-NEG-PST } \\ \text { 'Taro did not pick flowers in the garden.' } & \end{array}$

Under the present analysis, reduplicated nouns bear an uninterpretable valued number feature, and hence number neutral, just like bare common nouns. Their denotations correspond to the 
entire semilattice as in (12), including singular entities, and the similarity between (16a) and (17) follows from the present analysis.

4.3. NUMBER NEUTRALITY AND ELLIPSIS. Kramer (2017) uses ellipsis as a test for number neutrality. (18) shows that an interpretation of lexically ambiguous words such as pen in English must be carried over to an ellipsis site. (18) is true only when Lee and Sam saw the same type of entity in a context.

(18) English (Kramer 2017: 41)

Lee saw a pen and Sam did, too.

${ }^{\mathrm{OK}}$ 'Lee saw a writing implement, and Sam saw a writing implement, too.'

${ }^{\mathrm{OK}}$ 'Lee saw an animal enclosure, and Sam saw an animal enclosure, too.'

*‘Lee saw a writing implement, and Sam saw an animal enclosure.'

*'Lee saw an animal enclosure, and Sam saw a writing implement.'

On the other hand, an interpretation of number-neutral nouns can vary, regarding the singularplural distinction. Amharic bare nouns are number neutral like Japanese. When a bare noun is used with ellipsis, the resulting sentence becomes four-way ambiguous, as in (19).

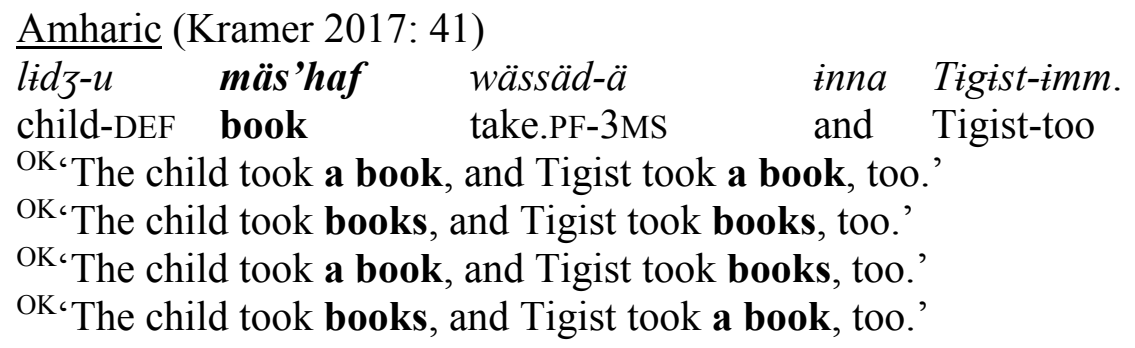

The contrast between (18) and (19) shows that Amharic bare common nouns are number neutral not because they are lexically ambiguous between singular and plural. Rather, the ambiguity of bare common nouns comes from other sources. Importantly, Japanese bare common nouns behave like Amharic bare common nouns in this respect. (20) exhibits a four-way ambiguity like (19). I do not commit to any particular analysis of ellipsis in (20). Of importance here is that interpretations of Japanese bare common nouns do not have to be carried over to an elided constituent. This means that number-neutrality of Japanese bare common nouns are not lexical ambiguity.
(20) Japanese
Taro-ga [Nihon-no sima]-o otozureta si, Hanako-mo otozureta.
Taro-top Japan-GEN island-acc visited and Hanako-also visited
OK'Taro visited Japanese islands and Hanako also visited Japanese islands.'
OK'Taro visited a Japanese island and Hanako also visited a Japanese island.'
OK‘ Taro visited Japanese islands and Hanako also visited a Japanese island.'
OK‘Taro visited a Japanese island and Hanako also visited Japanese islands.'

A detailed analysis of the four-way ambiguity in (20) requires a careful research on syntax and semantics of ellipsis, and goes far beyond the scope of this paper. However, the important point here is the fact that Japanese bare common nouns allow mismatch readings in which an elided noun and its antecedent are different from each other with respect to their number features.

Let us now consider plural reduplication in Japanese. As shown in (21), reduplicated nouns do not allow a singer interpretation, but they allow the mismatch between an elided noun and its 
antecedent, like bare common nouns. Under the mismatch reading, (21) is true in a situation where Taro visited more than one Japanese island and Hanako visited one Japanese island.

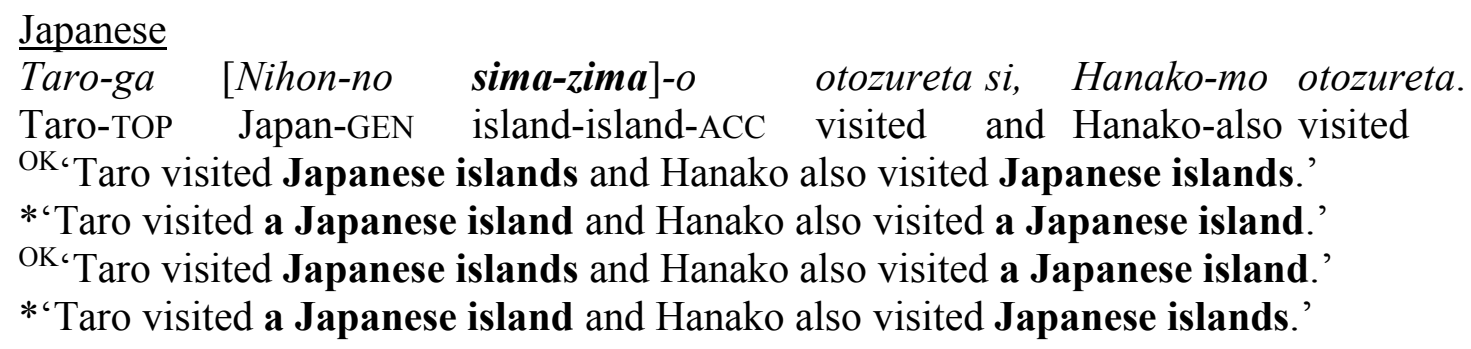

Under the current analysis, reduplicated nouns cannot receive a singular interpretation, because they are associated with an uninterpretable valued number feature. However, the denotation of a reduplicated noun corresponds to an entire semilattice containing singular individuals, like bare common nouns. As Karmer (2017) reported, the ambiguity in question arises with number-neural nouns but not with lexically ambiguous nouns. If the mismatch readings in (20) come from a property of number-neutral nouns, the availability of the mismatch reading in (21) suggests that reduplicated nouns in Japanese are similar to bare common nouns, regarding number neutrality.

4.4. KIND PREDICATES. According to Chierchia' $(1998,2010)$ approach to bare nominals, denotations of Japanese bare common nouns correspond to the entire semilattice as in (12), and they can function as a kind-denoting term. As can be seen in (22a), bare nouns can be used as an argument of a kind predicate. Importantly, reduplicated nouns can also function as an argument of a kind predicate, as shown in (22b). On the other hand, quantized nouns cannot be used as an argument of a kind predicate. (22c) is unacceptable because the kind predicate 'evolve' is incompatible with nouns other than kind-denoting terms.

$$
\begin{aligned}
& \frac{\text { Japanese }}{\text { a. hati-o hikiyoseru yooni [hana-wa sinka-sita]. }} \\
& \text { bee-ACC attract to flower-TOP evolution-did } \\
& \text { 'Flowers evolved to attract bees.' } \\
& \begin{array}{llll}
\text { b. hati-o hikiyoseru } & \text { yooni } & \text { [ hana-bana-wa } & \text { sinka-sita]. } \\
\text { bee-ACC attract } & \text { to } & \text { flower-flower-TOP } & \text { evolution-did }
\end{array} \\
& \text { 'Flowers evolved to attract bees.' } \\
& \text { c.\#hati-o hikiyoseru yooni [ni-hon-izyoo-no hana-wa sinka-sita]. } \\
& \text { bee-ACC attract to two-CLS-more.than-GEN flower-TOP evolution-did } \\
& \text { Lit. 'Two flowers evolved to attract bees.' }
\end{aligned}
$$

Under the current analysis of plural reduplication, the similarity between bare common nouns and reduplicated nouns is expected. According to Chierchia's analysis of bare nominals, the extension of a kind corresponds to the totality of its instances in a given world. Japanese bare common nouns and reduplicated nouns have the same denotation under the present analysis, and they behave alike.

4.5. GENERICS. There is another similarity between reduplicated nouns and bare common nouns. They can receive generic interpretations in Japanese, as shown in $(23 a, b)$. (23a,b) can be interpreted as characterizing statements about the flower-kind. On the other hand, quantized nouns cannot receive generic interpretations as in (23c). 
a. hana-wa ne-kara mizu-o sui-ageru.

flower-TOP root-from water-ACC suck-up

'It is a general property of flowers that they suck up water from roots.'

b. hana-bana-wa ne-kara mizu-o sui-ageru.

flower-flower-TOP root-from water-ACC suck-up

'It is a general property of flowers that they suck up water from roots.'
c. ni-rin izyoo-no
hana-wa ne-kara mizu-o
sui-ageru.
2-CLS more.than-GEN flower-TOP root-from water-ACC suck-up
'There is more than one flower that sucks up water from roots.'
*'It is a general property of flowers that they suck up water from roots.'

Chierchia's (1998) assumes that generic sentences contain the generic operator Gn, and when a kind-denoting term is used as the subject of a generic sentence, it provides a restrictor for the generic operator, in tandem with the $\cup$ function. Importantly, what appears in the restriction of the generic operator is a variable over instances of a given kind. Under this analysis of generic sentences, it will be predicted that Japanese plural reduplication and bare common nouns allow the generic interpretations in (23), in contrast to quantized nouns, because their denotations correspond to the entire semilattice as in (12). In this respect, plural reduplication in Thai shows a similar behavior, as shown in (24).

$$
\begin{aligned}
& \text { Thai (Jenks 2011: 109) } \\
& \text { dèk-dèk tàm kwaa phûu-jaj } \\
& \text { child-child short exceed adult } \\
& \text { 'The (group of) children are shorter than adults.' } \\
& \text { 'Children are shorter than adults' }
\end{aligned}
$$

[non-generic reading] [generic reading]

Jenks (2011) reports that (24) is ambiguous between the generic interpretation and the nongeneric interpretation. In Japanese, although the non-generic interpretation is possible in (23a,b), the generic interpretation is strongly preferred over a non-generic interpretation like 'A group of flowers suck up water from roots'. The preference of the generic interpretation in Japanese may arise from the presence of the topic marker $-w a$, but a full analysis of the preference goes beyond the scope of this paper. What is noteworthy about $(23 a, b)$ is that the reduplicated noun can receive the generic interpretation, like bare common nouns.

To recapitulate, the data in this section show that Japanese reduplicated nouns and bare common nouns behaves alike in many respects. The similarity can be seen as support for the present analysis in which reduplicated nouns bear an uninterpretable valued number feature.

5. Implication and typological variation. Nomoto (2013) reports that plural reduplication in Malay is incompatible with kind predicates as in (25a), whereas bare common nouns can cooccur with kind predicates as in (25b).

Malay (Nomoto 2013: 31)

a.\#Telefon-telefon di-cipta oleh Alexander Graham Bell pada tahun 1876. telephone-telephone PASS-invent by Alexander Graham Bell at year 1876 'The telephone was invented by Alexander Graham Bell in 1876.'
b. Telefon di-cipta oleh Alexander
Graham Bell pada tahun 1876.
telephone PASS-invent by Alexander Graham Bell at year 1876
'The telephone was invented by Alexander Graham Bell in 1876.' 
The contrast between (23b) and (25a) shows that the process of plural reduplication is not uniform. A similar typological variation is observed with respect to generic sentences. Unlike plural reduplication in Japanese and Thai, it has been reported that plural reduplication in Indonesian and Javanese cannot receive generic interpretations, as shown in (26) and (27).

(26) Indonesian (Sato 2008: 252 see also Sneddon 1996: 17)

Anjing-anjing menggonggong.

OK 'There is more than one dog that \{barks | is barking\}.'

* 'It is a general property of dogs that they bark.'

[non-generic reading] [generic reading]

(27) Javanese (Sato 2008: 263)

Asu-asu njegug.

dog-dog bark

OK 'There is more than one dog that $\{$ barks | is barking $\}$.'

* 'It is a general property of dogs that they bark.'

[non-generic reading]

[generic reading]

Under the present analysis, there may be some room for the cross-linguistic variation of plural reduplication. Harbour (2014) proposes that there is a parameter with respect to the availability of feature recursion as in (28).

(28) Feature Recursion Parameter (Harbour 2014: 200)

Both values of $[ \pm \mathrm{F}]$ may cooccur on $\mathrm{X}^{0}$.

Based on Harbour's proposal, I suggest that Japanese and Thai do not allow feature recursion of number features on a single head. In these languages, two opposite values of number features result in an uninterpretable valued number feature on the top node of a reduplicated noun, as represented in (7b). On the other hand, Indonesian, Javanese and Malay may allow feature recursion of number features, and two opposite values of number features do not yield an uninterpretable valued feature on the top node of a reduplicated noun. In other words, reduplicated nouns will retain two opposite values of interpretable number features in these languages. I leave a detailed analysis of plural reduplication in Indonesian, Javanese and Malay for future research. However, the current analysis of plural reduplication at least can provide room for the typological variation of plural reduplication. It may be worth noting here that classifiers are obligatory with numerals in Japanese and Thai, whereas they are optional in Indonesian and Malay. This contrast may also be related to the typological variation of plural reduplication. Moreover, the present analysis can make a prediction that a process of reduplication can be associated with nominal plurality only in languages where bare nouns are ambiguous between singular and plural.

6. Summary. In this paper, I argued that Japanese reduplicated nouns are antonym compounds that have two opposite values of number features. Based on Harbour (2011), I proposed that two opposite values yield an uninterpretable valued number feature on the top node of a reduplicated noun. Uninterpretable features do not have any semantic import, and the proposal predicts that reduplicated nouns are similar to bare common nouns in the sense that they do not bear the singular-plural distinction. I showed that reduplicated nouns in Japanese indeed behave like bare common nouns in many respects. Moreover, the proposed analysis can provide room for typological variation of plural reduplication, and it makes a typological prediction about the 
availability of plural reduplication. I leave for future research a detailed analysis of the typological variation and an investigation of the prediction.

\section{References}

Chierchia, Gennaro. 1998. Reference to kinds across languages. Natural Language and Semantics 6. 339-405. https://doi.org/10.1023/A:1008324218506.

Chierchia, Gennaro. 2010. Mass nouns, vagueness and semantic variation. Synthese 174. 99-149. https://doi.org/10.1007/s11229-009-9686-6.

Harbour, Daniel. 2011. Valence and atomic number. Linguistic Inquiry 42. 561-594. https://doi.org/10.1162/LING_a_00061.

Harbour, Daniel. 2014. Paucity, abundance, and the theory of number. Language 90(1). 185-229. https://doi.org/10.1353/lan.2014.0003.

Inkelas, Sharon, and Zoll, Cheryl. 2005. Reduplication: Doubling in morphology. Cambridge: Cambridge University Press.

Jenks, Peter. 2011. The Hidden Structure of Thai Noun Phrases. Cambridge, MA: Harvard University dissertation.

Kramer, Ruth. 2017. General number nouns in Amharic lack NumP. In Jason Ostrove, Ruth Kramer, and Joseph Sabbagh (eds.), Asking the Right Question: Essays in Honor of Sandra Chung. Santa Cruz: Linguistics Research Center.

Kurafuji, Takeo. 2004. Plural morphemes, definiteness, and the notion of semantic parameter. Language and Linguistics 5. 211-242.

Nakanishi, Kimiko and Satoshi Tomioka. 2004. Japanese plurals are exceptional. Journal of East Asian Linguistics 13. 113-140. https://doi.org/10.1023/B:JEAL.0000019058.46668.c1.

Nomoto, Hiroki. 2013. Number in classifier languages. Minneapolis: University of Minnesota dissertation.

Pesetsky, David, and Esther Torrego. 2007. The syntax of valuation and the interpretability of features. In Simin Karimi, Vida Samiian \& Wendy Wilkins (eds.), Phrasal and clausal architecture. 262-294. Amsterdam: John Benjamins.

Sato, Yosuke. 2008. Minimalist Interfaces: Selected issues in Indonesian and Javanese. University of Arizona dissertation.

Sneddon, James Neil. 1996. Indonesian: A Comprehensive Grammar. London: Routledge.

Sudo, Yasutada. 2015. Notes on the semantics of nouns and classifiers in Japanese. Handout at Workshop on Altaic Formal Linguistics 11. University of York, UK.

Yuta, Tatsumi. 2017. A compositional analysis of plural morphemes in Japanese. In Michael Yoshitaka Erlewine (ed.), Proceedings of GLOW in Asia XI vol II, MIT Working Papers in Linguistics, 85. 233-241. 